\title{
Forecasting Parameters of Satellite Navigation Signal through Artificial Neural Networks for the Purpose of Civil Aviation
}

\author{
Karolina Krzykowska (iD) ${ }^{1}$ and Michał Krzykowski ${ }^{2}$ \\ ${ }^{1}$ Department of Telecommunication in Transport, Faculty of Transport, Warsaw University of Technology, Warsaw 00-662, Poland \\ ${ }^{2}$ Department of Civil Law II \& Economic Law, Faculty of Law \& Administration, University of Warmia and Mazury in Olsztyn, \\ Olsztyn 10-719, Poland
}

Correspondence should be addressed to Karolina Krzykowska; krzykowskakarolina@gmail.com

Received 27 November 2018; Revised 16 February 2019; Accepted 4 March 2019; Published 30 April 2019

Academic Editor: Angelo Cervone

Copyright (c) 2019 Karolina Krzykowska and Michał Krzykowski. This is an open access article distributed under the Creative Commons Attribution License, which permits unrestricted use, distribution, and reproduction in any medium, provided the original work is properly cited.

\begin{abstract}
Navigation is a key element influencing fluent, rapid, and safe transport of people and goods. During the last years, special attention was paid to satellite navigation, which is a part of radionavigation where positioning is done thanks to artificial satellites. Issues of application and development of satellite navigation systems in civil aviation are the subject of numerous research and scientific studies in the world. The quality of satellite signal determined by parameters such as accuracy, continuity, availability, and integrity determines possibility of its operational use. Particular attention of scientific research is therefore devoted to the requirements and limitations imposed on satellite systems prior to their implementation in aviation. This extremely important aspect justified undertaking of the aforementioned problem in this article. The paper attempts to answer the question on how to facilitate selection of navigation techniques for the aircraft operator, taking into account factors determining the accuracy, continuity, availability, and integrity of the satellite signal. As a result, the purpose of the work was defined as development of a method for forecasting the values of satellite navigation signal parameters used in air transport by artificial neural networks, taking into account selected atmospheric conditions. Results included in the work indicate further directions of satellite navigation system development. Due to authors' opinion, the researches should focus especially on the analysis of real-time satellite signal parameter performance or creating applications for UAVs automatically deciding about used techniques of navigation.
\end{abstract}

\section{Introduction}

Aviation is one of the fastest growing branches of transport, not only because of the number of passengers or flight operations but also thanks to intensive implementation of new technologies in the industry. These technologies, in air transport, are generally referred to CNS (communication, navigation, and surveillance). Transport will not function properly without these services being provided. It can therefore be concluded that the dynamic progress in modernizing CNS techniques can directly or indirectly affect the attractiveness of air transport for users. On June 21st, 2018, the Polish project of operational implementation of instrumental approach procedures for landing using satellite signal supported by an SBAS (satellite-based augmentation system)-EGNOS (European Geostationary Navigation Overlay Service)—was completed. This made Poland one of the few countries in which such approach procedures were applied at the majority of controlled airports present in the FIR (flight information region) Warsaw. Requirements for adopted procedures were based on the minima from the instrument landing approach ILS (instrument landing system) cat. I. They refer to four main signal parameters and include the following:

(1) Accuracy: (i) horizontal accuracy (16 m) and (ii) vertical accuracy $(4 \mathrm{~m})$ 
(2) Integrity measured by a number of misleading information $\left(1-2 \times 0^{-7} / \mathrm{h}\right)$ and time to alert $(6 \mathrm{~s})$

(3) Continuity measured by discontinuity events $\left(1-8 \times 10^{-6} / \mathrm{h}\right.$ during $\left.15 \mathrm{~s}\right)$

(4) Availability on the level from 0.99 to 0.99999

It can therefore be concluded that satellite systems and signals provided by them are a key element in the development of strategy of civil aviation systems. It can not be overlooked that the limited operational use of satellite systems in air transport is caused by various errors that are inherent to the work of these systems. The satellite system, in all its complexity, can be treated as a measurement system-accuracy of which is one of its most important features [1].

The article's research problem concerns on the use of information about atmospheric factors that disrupt the satellite signal to forecast the value of signal parameters (accuracy, continuity, availability, and integrity). The rationale for this choice is, inter alia, that satellite systems are considered to be the future of navigation and surveillance in aviation. Failure in meeting signal requirements prevents their operational use. What is important, in the processes of air traffic management, is that such systems are commonly used in all phases of flight, and thus, determining and predicting signal parameters become an important problem.

Research topics including the influence of atmospheric phenomena on satellite signal parameters are widely described in the literature on the subject. A review of this literature made for the purposes of the article also points out many studies conducted in the field of modeling and prediction of signal parameters through artificial neural networks. However, no detailed studies that would include use of tropospheric, ionospheric, and historical data to forecast values of signal parameters in application to navigation in air transport have been found so far. Their implementation will therefore have a significant impact on the development of science in this area. The layout of the article will be as follows: in the next chapter, a review of world literature in this area was carried out and the state of the art was presented. Secondly, the methodology of research was approximated in the context of a given research problem. In the next step of procedure, the researches were presented and their results were analyzed. The last chapter proposes directions for further research.

\section{Literature Review and the State of the Art}

Already in publications from 2000, there was visible interest in satellite systems in application to various fields of engineering. Even though, originally, the GPS (global positioning system) was created for navigational activities, it was quickly discovered that it has numerous purposes, such as surveying, determining the place of rapid seismic movements, or relocating bridges and other large engineering structures [2]. It turned out, however, that the use of the GPS entails the necessity to correct errors caused by the atmosphere or the signal reflection in determining the position [3]. In the article from 2016, a method of elimination of GNSS multiverbal errors with the use of an integrated measurement system and artificial neural networks was proposed [4]. In another source, a new method of improving the positioning efficiency measured by pseudoranges in the degraded signal environment has been proposed. This method is intended to reduce the loss of measurement accuracy by introducing an additional parameter to the model, which includes time scale difference, hardware delays, and correction of measurement errors between the respective satellites and reference points [5]. Importantly, there are also works related to the study of the influence of external factors on the quality of the satellite signal. The team of Ordóñez Galán et al. uses artificial neural networks to analyze the accuracy of measurements made with the GNSS technology in case if the GPS receiver is in a wooded environment. Measurements were made every second, for one hour at twelve different points in the forest area. Each point was characterized by a slightly different external environment (tree density, tree volume, etc.). First of all, the position error, the signalto-noise ratio, and the number of satellites available for the measurement were examined. As a result of the experiment, a model of artificial neural networks was proposed in which the given conditions were dynamically taken into account over time [6]. More similar studies are described in the publications $[7,8]$.

The literature also touched the important issue of signal integrity. It is a measure of the probability that can be attributed to the correctness of information provided by the navigation system. In EGNOS, its mapping are values of protection levels monitored during system operation [9]. Monitoring of the integrity of the system's operation is possible thanks to RAIM (receiver autonomous integrity monitoring). RAIM is a software that validates the information received from satellites using only the signal from a given satellite navigation system, e.g., by comparing the position determined by different combinations of signals from various sets of satellites observed. According to new sources, the alternative for RAIM is to be SAIM (satellite autonomous integrity monitoring) [10-13].

In view of the received satellite signal, an appropriate amendment should be adopted, taking into account its passage through various layers of the atmosphere. For example, to determine the correction taking into account the course of signal through the ionosphere, the vertical component of the electron density TEC (total electron content) is assumed. This is the total number of electrons gathered between two points along a column with a crosssection of $1 \mathrm{~m}^{2}$ and the base of the rectangle. Due to the significant influence of TEC on the quality of the received satellite signal, much attention was focused on the prediction of TEC, also using artificial neural networks [14-18]. It is worth paying attention to the methodology of research conducted in the aforementioned studies [18-20]. It is similar to the one established in this article. Also, in articles [21, 22], neural networks for forecasting navigation values and communication techniques were used, which makes them useful in various studies-the effect of which is to be a predictive model. 
TABLE 1: Comparison of network structure in individual models.

\begin{tabular}{lcccc}
\hline & $\begin{array}{c}\text { Model ANN 1. } \\
\text { Accuracy }\end{array}$ & $\begin{array}{c}\text { Model ANN 2. } \\
\text { Continuity }\end{array}$ & $\begin{array}{c}\text { Model ANN 3. } \\
\text { Availability }\end{array}$ & $\begin{array}{c}\text { Model ANN 4. } \\
\text { Integrity }\end{array}$ \\
\hline Number of neurons for input & 5 & 6 & 6 & 6 \\
Number of neurons in the output layer & 1 & 1 & 1 & 1 \\
Number of hidden layers & 1 & 1 & 2 & 1 \\
Number of neurons in the hidden layer & 1 & 8 & $70 / 15 / 15$ & $70 / 15 / 15$ \\
Division of the training set & $70 / 15 / 15$ & $80 / 10 / 10$ & Levenberg-Marquardt & Levenberg-Marquardt \\
Training algorithm & Levenberg-Marquardt & Levenberg-Marquardt & Levend
\end{tabular}

Source: own study based on structures of artificial neural networks in MALTAB Neural Network Toolbox.

\section{Causes of Limited Operational Use of Satellite Systems in Aviation}

The prior inspiration for research was an analysis of liability for damages arising with the lack of availability of GNSS navigation when an aircraft is taking an approaching procedure. A question was to which regulations should be invoked in the event of damage or incident resulting from disturbances or discontinuities associated with the GNSS navigation. After putting up this question, a new problem arose. The causes of GNSS signal disturbances include law regulations, cooperation of systems and service providers, and, most of all, technical aspects of the satellite signal.

Important limitations affecting the implementation of satellite systems in aviation have their sources in legal and administrative aspects. International cooperation in the field of law relating to satellite systems is an important factor in the context of the limited operational use of such systems. So far, bilateral or multilateral agreements concluded both by countries and organizations (ESA, EU, and EUROCONTROL) can be found in this area. Such a solution could also be used by the United States of America and Russia, which would improve and regulate the access to the two largest satellite systems (GPS and GLONASS). So far, the standards of GNSS system implementation and development are regulated by organizations such as ICAO (International Civil Aviation Organization) or IMO (International Maritime Organization). Maintaining a high level of quality of regulatory solutions in the field of satellite systems is crucial. The rate of market growth in the satellite navigation sector is $25 \%$ per annum. The global space sector in 2007 had a revenue of 251 billion USD, which is over twice as much as the entire Polish budget. In 2020, the satellite market may be worth around 300 billion Euro. For Europe, the most important goal remains the development and implementation of the Galileo satellite system.

The application of the space law to aviation and vice versa is also questionable. Many representatives of the legal doctrine consider it unacceptable to apply aviation regulations to space activities, mainly due to the specific construction of aviation law distinguishing the sovereignty of states in air space above their territory. In Polish literature, however, you can meet different points of view. Berezowski et al. explains that the international aviation law regulates relations other than land or water, which indicates the possibility of treating space and air together in aviation [23]. However,
TABLE 2: Values of MSE and $R$ depending on the number of neurons in the hidden layer in model ANN 1.

\begin{tabular}{llc}
\hline $\begin{array}{l}\text { Number of neurons } \\
\text { in the hidden layer }\end{array}$ & MSE value & $R$ value \\
\hline 1 & $1.523 \times 10^{-3}$ & 0.483 \\
2 & $2.382 \times 10^{-3}$ & 0.486 \\
3 & $2.162 \times 10^{-3}$ & 0.528 \\
5 & $2.467 \times 10^{-3}$ & 0.526 \\
10 & $1.607 \times 10^{-3}$ & 0.527 \\
\hline
\end{tabular}

Source: own study in MALTAB Neural Network Toolbox.

TABLE 3: Values of MSE and $R$ depending on the training algorithms (for one neuron in the hidden layer) in model ANN 1.

\begin{tabular}{lcc}
\hline Training algorithm & MSE value & $R$ value \\
\hline Levenberg-Marquardt (TRAINLM) & $1.523 \times 10^{-3}$ & 0.483 \\
$\begin{array}{l}\text { Bayesian regularization (TRAINBR) } \\
\text { The smallest pitch drop algorithm }\end{array}$ & $2.714 \times 10^{-3}$ & 0.248 \\
\begin{tabular}{l} 
(TRAINGDM) \\
\hline
\end{tabular} & $2.558 \times 10^{-3}$ & 0.427 \\
\hline
\end{tabular}

Source: own study in MALTAB Neural Network Toolbox.

TABle 4: Values of MSE and $R$ depending on the division of the training set (for one neuron in the hidden layer and TRAINLM algorithm) in model ANN 1.

\begin{tabular}{lcc}
\hline Division of the training set & MSE value & $R$ value \\
\hline $70 \% / 15 \% / 15 \%$ & $1.523 \times 10^{-3}$ & 0.483 \\
$80 \% / 10 \% / 10 \%$ & $2.661 \times 10^{-3}$ & 0.034 \\
\hline
\end{tabular}

Source: own study in MALTAB Neural Network Toolbox.

this problem still remains unexplained considering the very dynamic development of technology in the field of both aviation and astronautics. Currently, we already have to deal with objects such as space planes or flying devices. In the future, one can therefore expect the necessity to establish new regulations that will determine the rules of using such vehicles [24]. 


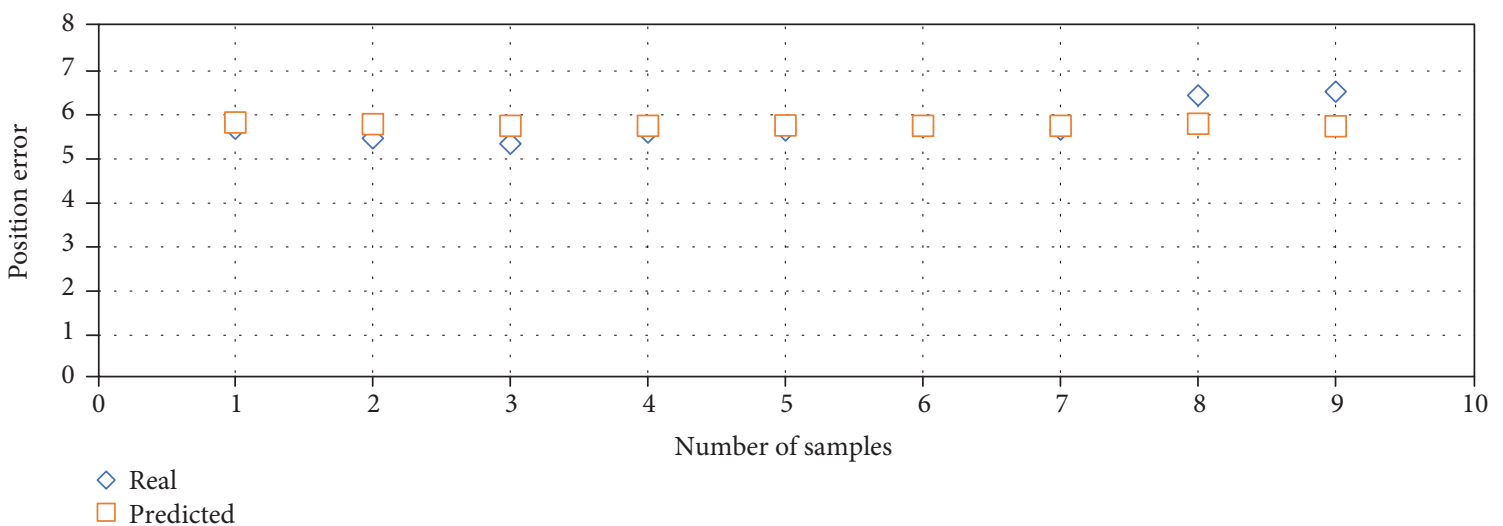

Figure 1: Comparison of the forecast and actual position error of the signal.

Particularly unregulated are also extremely important issues of liability for damages arising with the participation of an aircraft. A question is to which regulations should be invoked in the event of damage or incident resulting from disturbances or discontinuities associated with the operation of GNSS. Modern technology allows the action known as meaconing or MIJI (Meaconing, Intrusion, Jamming, and Interference) to disturb and silence received radio signals and then to retry again transmitting other beacons in order to confuse the navigator, as a result of which aircraft or ground stations receive inaccurate indications of object position. Such situations lead to an aircraft deviating from the course and even to its accident. Here, it is worth referring to [25] or [26], which, however, only to a limited extent, corresponds to the need of sanctioning such acts.

The limited operational use of satellite systems can be caused by various errors that are inherent in the work of these systems. In general, the errors of satellite systems can be divided into four groups:

(1) Signal propagation errors, including (i) ionospheric errors, (ii) tropospheric errors, and (iii) multitrack errors

(2) Relativistic errors

(3) System operation errors (these are errors originating mainly in the space segment of the satellite system, but sometimes also in the terrestrial segment), including (i) satellite ephemeris errors and (ii) satellite clock errors

(4) Receiver errors (this group of errors is generated in the user segment), including the DOP (dilution of precision) error

For this work, authors focused on ionospheric and tropospheric errors only.

The ionospheric error arises due to the delay of the satellite signal passage through the ionosphere. Alternatively, it can be called ionospheric delay or ionospheric refraction. It results from a change in the signal path and change in phase speed of the wave (signal) as well as the frequency of the carrier wave. This leads to change in the signal travel time [27]. The state of the ionosphere remains also under the influence of solar activity, manifested by changes occurring on the surface of the Sun and its atmosphere. These changes cause the fluctuations of radiation that reaches the Earth in the form of electromagnetic waves, including light, and the stream of particles emitted by the Sun (solar wind). Solar activity includes also changes in the number and distribution of sunspots. The basic cycle of changes in solar activity is about 11 years. In one such cycle, the Sun changes the level of activity from the minimum to the next minimum [28].

The tropospheric error, also called tropospheric delay, is caused by both the dry troposphere and the moist troposphere. By the dry part, one should understand the atmospheric pressure, the air density, and its temperature, changing with altitude. It is assumed that the dry matter causes almost $90 \%$ of the tropospheric error (delay). The moist part of the troposphere is closely related to the very high content of water vapor in this atmosphere layer. This content results from the weather in troposphere-the presence of clouds and rainfall causes almost $99 \%$ of moisture in the lowest part of the atmosphere (counting surface waters of the Earth as well). The content of water vapor depends on the altitude and atmospheric phenomena (storms, fronts), too [29].

Nevertheless, satellite systems are considered to be the future of navigation. They are constantly subject of projects and even entire research programs, in which the main goal is to develop the product. The similarity of the satellite navigation system structure means that some general directions of action can be identified until 2020. The main changes are the technical ones in space and terrestrial segments that will enable, among others, to extend the satellite's time of saturation, broadcast new signals on additional frequencies, increase the accuracy of measurements (especially in conditions of large urban development and other limitations of signal transmission), and increase the resistance of signal to interference. From the user's point of view, the 
information about the quality of the satellite signal provided and therefore the quality of the service is important. In case of the need to provide qualitative information (yes-GNSS navigation will be accurate, available, continuous, and integral or no-GNSS navigation will be either not accurate or not available, not continuous, and not integral for the exact period of time), the solution might be a quality-type alert in the GNSS panel dependent on forecast time, e.g., yellow bar with information that the GNSS signal may be lost in 1 hour or red bar with information that GNSS signal may be lost in $10 \mathrm{~min}$. In case of the need to provide quantitative information, the best solution seems to be sending information about the parameters of the satellite signal and forecasted via a NOTAM message, especially that the "NOTAM D" has dedicated space for such an information. This would therefore require taking appropriate regulatory actions at the global level. Still, forecasting signal parameters seems to be a solution that allows users to choose the method and technology of work that is conducive to perform operation maintaining the highest possible level of security [30].

\section{Research Methodology}

Artificial neural networks (ANN) are treated as an attempt to use phenomena occurring in nervous systems to solve research problems. The inspiration for their creation was the nervous system of a man who, after all, controls his body and mind. According to the researchers, artificial reproduction of such a system enables modeling and controlling processes occurring in the world of new technologies. ANN are currently used in areas such as electronics, cybernetics, automation, or mechanics.

Sigmoid neuron belongs to one of the most popular group of neurons enabling construction of the perceptron multilayer neural network (MLP-multilayer perceptron). At the same time, it is worth emphasizing that the nonlinear sigmoid neuron is the most similar in functioning to the biological nerve cell. Multilayered perceptron (MLP) is a oneway type of neural network, in which neurons are arranged in layers (input, output, and hidden). Typically, networks with one or two hidden layers are built. The MLP network is trained by back propagation error method-typical for one-way networks (or the so-called feedforward networks) in which the flow of signals takes place only from the input to the output. In general, training is defined as the process of educating the network through the presentation of examples of the correct solution to the research problem. On this basis, the network attempts to solve the problem. After that, solutions are compared with the standards and the size of the error is determined as well. It is a natural phenomenon to strive for its minimization and hence long-term training of network. The length of training in this context refers to the number of examples of correct solution to the research problem. They belong to the so-called training set of the network - the main data set occurring in the process of building a neural network. A part of the training set (usually up to $20 \%$ ) is isolated to the so-called validation set. It is used for periodic validation of the network, which is aimed at
TABLE 5: Values of MSE and $R$ depending on the number of neurons in the hidden layer in model ANN 2.

\begin{tabular}{llc}
\hline $\begin{array}{l}\text { Number of neurons } \\
\text { in the hidden layer }\end{array}$ & MSE value & $R$ value \\
\hline 1 & $1.727 \times 10^{-3}$ & 0.792 \\
2 & $2.750 \times 10^{-3}$ & 0.833 \\
5 & $2.602 \times 10^{-2}$ & 0.114 \\
8 & $1.390 \times 10^{-3}$ & 0.831 \\
10 & $2.760 \times 10^{-3}$ & 0.787 \\
\hline
\end{tabular}

Source: own study in MALTAB Neural Network Toolbox.

TABLE 6: Values of MSE and $R$ depending on the training algorithms (for eight neurons in the hidden layer) in model ANN 2.

\begin{tabular}{lcc}
\hline Training algorithm & MSE value & $R$ value \\
\hline Levenberg-Marquardt (TRAINLM) & $1.390 \times 10^{-3}$ & 0.831 \\
Bayesian regularization (TRAINBR) & $1.476 \times 10^{-3}$ & 0.281 \\
$\begin{array}{l}\text { The smallest pitch drop algorithm } \\
\text { (TRAINGDM) }\end{array}$ & $1.731 \times 10^{-3}$ & 0.838 \\
\hline
\end{tabular}

Source: own study in MALTAB Neural Network Toolbox.

TABLE 7: Values of MSE and $R$ depending on the division of the training set (for eight neurons in the hidden layer and TRAINLM algorithm) in model ANN 2.

\begin{tabular}{lcc}
\hline Division of the training set & MSE value & $R$ value \\
\hline $70 \% / 15 \% / 15 \%$ & $3.996 \times 10^{-3}$ & 0.851 \\
$80 \% / 10 \% / 10 \%$ & $1.390 \times 10^{-3}$ & 0.831 \\
\hline
\end{tabular}

Source: own study in MALTAB Neural Network Toolbox.

eliminating the phenomenon of overfitting. If the size of the training set allows it, it is worth separating one more set-the test one. It should be about $10 \%$ of randomly selected training cases and is used for one-time network control after training. The optimal situation is when the test set can be a set of data from the examined phenomenon in which real anomalies occurred. The network then can actually demonstrate the ability to detect them [31].

The selection of data sample, determination of sets, and choice of the training algorithm are extremely important for models proposed in the article and final modeling result, which is the forecast. In the study, authors used measurements from the Warsaw station made in 2014 for the EGNOS satellite PRN120 during the APV-I vertical approach and a comparison of atmospheric conditions (cloudiness, humidity, precipitation, pressure, and temperature) from the same period and area. Supplement was data on solar activity. Four models were proposed corresponding to four satellite signal parameters: 


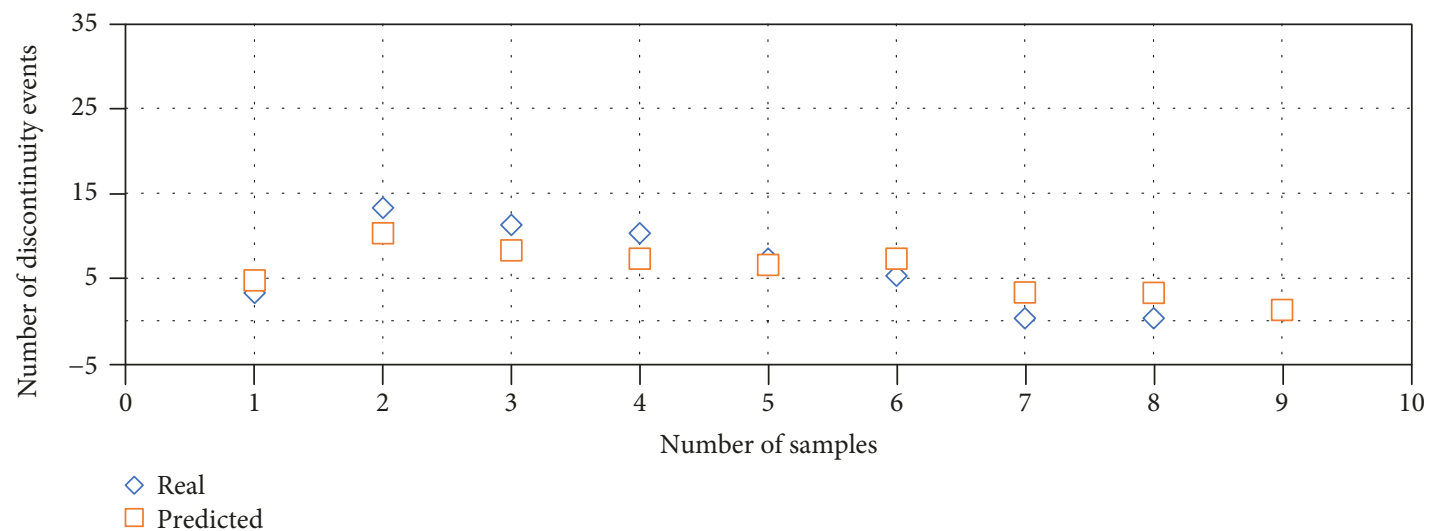

FIgURE 2: Comparison of the forecast and actual number of discontinuity events.

(i) Model ANN 1. Accuracy

(ii) Model ANN 2. Continuity

(iii) Model ANN 3. Availability

(iv) Model ANN 4. Integrity

Models were implemented to the MATLAB Neural Network Toolbox. Achieving satisfactory and at the same time optimal results was possible only by testing different model configurations. Therefore, eventually, the models differ in the number of neurons in the hidden layers or the division of the training set on subsets. In each of the model, the sigmoidal activation function was used and the variable values were normalized to range from -1 to 1. In the structure of all models, there is one hidden layer. During the research, it could be clearly observed that such a system is the best for models, while others, especially with more hidden layers, caused network overtraining. In this case, the rule was found that the more the hidden layers, the greater the strength of the network and, also, the greater its tendency to overtrain. In the process of creating models, especially in anticipation on the results, it should be remembered that the analyzed research problem of the influence of selected atmospheric conditions on the satellite signal concerns only one of many aspects determining the form of this signal. The article though attempts to answer the following question: which atmospheric conditions and to what extent they affect the satellite signal and whether it is possible to model parameter values having exclusively data on these conditions occurring during the use and measurement of the signal?

There were two kinds of data determined: input data $(x)$ and output data $(y)$ :
(i) $x_{1}$-cloudiness
(ii) $x_{2}$-humidity
(iii) $x_{3}$-precipitation
(iv) $x_{4}$-temperature

TABLE 8: Values of MSE and $R$ depending on the number of neurons in the hidden layer in model ANN 3.

\begin{tabular}{llc}
\hline $\begin{array}{l}\text { Number of neurons } \\
\text { in the hidden layer }\end{array}$ & MSE value & $R$ value \\
\hline 1 & $6.520 \times 10^{-5}$ & 0.902 \\
2 & $3.908 \times 10^{-5}$ & 0.887 \\
5 & $5.513 \times 10^{-5}$ & 0.885 \\
8 & $8.808 \times 10^{-5}$ & 0.875 \\
10 & $9.001 \times 10^{-5}$ & 0.397 \\
\hline
\end{tabular}

Source: own study in MALTAB Neural Network Toolbox.

TABLE 9: Values of MSE and $R$ depending on the training algorithms (for two neurons in the hidden layer) in model ANN 3.

\begin{tabular}{lcc}
\hline Training algorithm & MSE value & $R$ value \\
\hline Levenberg-Marquardt (TRAINLM) & $3.908 \times 10^{-5}$ & 0.887 \\
Bayesian regularization (TRAINBR) & $9.139 \times 10^{-3}$ & 0.048 \\
$\begin{array}{l}\text { The smallest pitch-drop algorithm } \\
\text { (TRAINGDM) }\end{array}$ & $1.704 \times 10^{-4}$ & -0.007 \\
\hline
\end{tabular}

Source: own study in MALTAB Neural Network Toolbox.

TABLE 10: Values of MSE and $R$ depending on the division of the training set (for two neurons in the hidden layer and TRAINLM algorithm) in model ANN 3.

\begin{tabular}{lcc}
\hline Division of the training set & MSE value & $R$ value \\
\hline $70 \% / 15 \% / 15 \%$ & $3.908 \times 10^{-5}$ & 0.887 \\
$80 \% / 10 \% / 10 \%$ & $4.233 \times 10^{-5}$ & 0.050 \\
\hline
\end{tabular}

Source: own study in MALTAB Neural Network Toolbox. 


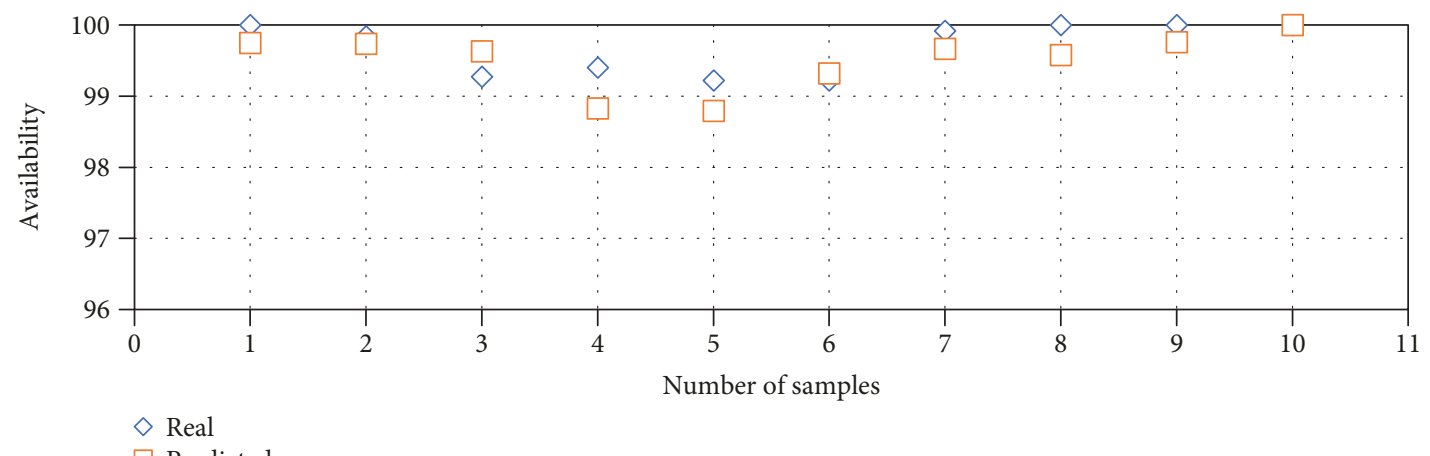

Figure 3: Comparison of the forecast and actual availability of the signal.

(v) $x_{5}$-pressure

(vi) $x_{6}$-solar activity

(vii) $y_{1}=x_{7}-$ position error

(viii) $y_{2}=x_{8}$-number of discontinuity events

(ix) $y_{3}=x_{9}$-availability

(x) $y_{4}=x_{10}$-protection level

The training set consisted of 181 samples; however, the set was divided into three subsets-training, validation, and test. Depending on the model, this division was in the $70 \% / 15 \% / 15 \%$ or $80 \% / 10 \% / 10 \%$ configuration. In addition, apart from the atmospheric conditions to the input of the network, the historical parameter data were added, i.e., in model ANN 1. Accuracy for input included $x_{4}, x_{6}, x_{8}, x_{9}, x_{10}$ and for output included variable $y_{1}$ etc. What is more, for individual models, the socalled best predicates were chosen and, therefore, those conditions, according to the expert research, hadthe greatest impact on a given parameter. In that case, the input signals (vector $X$ ) and output signals (vector $Y$ and reference vector $D$ ) for individual models were formulated as follows:

(i) For model ANN 1. Accuracy,

$$
\begin{aligned}
X_{i 1} & =\left[x_{i 4}, x_{i 6}, x_{i 8}, x_{i 9}, x_{i 10}\right]^{T}, \\
Y_{i 1} & =\left[y_{i 1}\right]^{T}, \\
D_{i 1} & =\left[d_{i 1}\right]^{T}
\end{aligned}
$$

(ii) For model ANN 2. Continuity,

$$
\begin{aligned}
X_{i 2} & =\left[x_{i 1}, x_{i 3}, x_{i 6}, x_{i 7}, x_{i 9}, x_{i 10}\right]^{T}, \\
Y_{i 2} & =\left[y_{i 2}\right]^{T}, \\
D_{i 2} & =\left[d_{i 2}\right]^{T}
\end{aligned}
$$

(iii) For model ANN 3. Availability,

$$
\begin{aligned}
& X_{i 3}=\left[x_{i 1}, x_{i 5}, x_{i 6}, x_{i 7}, x_{i 8}, x_{i 10}\right]^{T}, \\
& Y_{i 3}=\left[y_{i 3}\right]^{T}, \\
& D_{i 3}=\left[d_{i 3}\right]^{T}
\end{aligned}
$$

(iv) For model ANN 4. Integrity,

$$
\begin{aligned}
X_{i 4} & =\left[x_{i 3}, x_{i 5}, x_{i 6}, x_{i 7}, x_{i 8}, x_{i 9}\right]^{T}, \\
Y_{i 4} & =\left[y_{i 4}\right]^{T}, \\
D_{i 4} & =\left[d_{i 4}\right]^{T},
\end{aligned}
$$

where $i$ is the number of the next sample from the training set

Table 1 summarizes the basic information about the network in each model.

Different numbers of neurons in hidden layers have been determined as a result of testing many networks with different numbers of neurons. Each time a network giving optimal results following the basic criterion, the smallest error value MSE (mean squared error), was chosen. The additional criterion was the largest, in turn, value of the indicator $R$ (regression). It represents the relationship between values of vectors: actual $Y$ and standard $D$. When $R=1$, the relation between $Y$ and $D$ is linear. When $R$ turns to 0 , the relations seem to be nonlinear. The higher the value of $R$, the smaller the difference between $D$ and $Y$. Furthermore, the networks were analyzed in terms of different training algorithms. In the training process, the Levenberg-Marquardt (TRAINLM) algorithm, Bayesian regularization (TRAINBR), and the smallest pitch drop algorithm (TRAINGDM) were taken into account. The choice of these algorithms was dictated by their special features referring to the research problem, i.e., the possibility of memory reduction at large training sets, verifiability for small and moderately complicated network structures, and good generalization properties, avoiding network stuck in the local minimum function. The models used a simple validation (dividerand)—data set was randomly divided into three subsets: training, validation, and test. 


\section{Results and Discussion}

Artificial neural networks, in various configurations, built for the needs of four models have undergone training, validation, and testing processes. Different configurations of neural networks were tested in each of the models. However, always, the same rules were followed. Firstly, networks with different numbers of neurons in the hidden layer were tested (from 1 to 20 neurons in each model). The most representative networks were then selected. After the first step, these chosen networks were tested with different learning algorithms. The best ones were chosen again. At the end, different configurations of the training set division were tested and networks which achieved the smallest MSE value and the highest $R$ value were selected as champion ones. In the tables, the following are listed in sequence:

(i) Values of MSE and $R$ for a specific number of neurons in the network hidden layer

(ii) Values of MSE and $R$ with different training algorithms for the number of neurons in the network hidden layer for which the best result was previously obtained

(iii) Values of MSE and $R$ taking into account the different divisions of the training set into subsets with the chosen training algorithm and the number of neurons in the network hidden layer

The results of the satellite signal parameter forecast were also presented and verified with real data. The optimal values of tested networks are listed in tables. For each training, the weights were randomly generated-reinitialized (the initial values were given for the network weights). When designing them, regardless of the model, specific initial conditions were set in MATLAB Toolbox:

(i) Type of network-feed-forward backprop

(ii) Activation function-TANSIG (hyperbolic tangent)

(iii) Maximum number of epochs (iterations) -1000

(iv) Maximum duration of training $-\infty$

(v) Expected value of the objective function -0

(vi) Minimal size of the gradient $-1 \times 10^{-7}$

(vii) Number of validation checks-100

(viii) Objective function-MSE (mean square error)

In Table 2, the MSE error values and $R$ indicator for different numbers of neurons in the hidden layer for model ANN 1. Accuracy were presented. Many networks were tested, but the most representative results were seen for networks with one, two, three, five, or ten neurons in the hidden layer. However, apart from the network with one neuron in the hidden layer, the remaining ones have been overtrained, as evidenced by the significantly increasing MSE error. The
TABLE 11: Values of MSE and $R$ depending on the number of neurons in the hidden layer in model ANN 4.

\begin{tabular}{llc}
\hline $\begin{array}{l}\text { Number of neurons } \\
\text { in the hidden layer }\end{array}$ & MSE value & $R$ value \\
\hline 1 & $5.530 \times 10^{-4}$ & 0.308 \\
2 & $4.184 \times 10^{-4}$ & 0.266 \\
5 & $5.303 \times 10^{-4}$ & 0.356 \\
8 & $7.146 \times 10^{-4}$ & 0.263 \\
10 & $4.749 \times 10^{-4}$ & 0.444 \\
\hline
\end{tabular}

Source: own study in MALTAB Neural Network Toolbox.

TABle 12: Values of MSE and $R$ depending on the training algorithms (for two neurons in the hidden layer) in model ANN 4.

\begin{tabular}{lcc}
\hline Training algorithm & MSE value & $R$ value \\
\hline Levenberg-Marquardt (TRAINLM) & $4.184 \times 10^{-4}$ & 0.266 \\
Bayesian regularization (TRAINBR) & $1.022 \times 10^{-2}$ & -0.332 \\
$\begin{array}{l}\text { The smallest pitch drop algorithm } \\
\text { (TRAINGDM) }\end{array}$ & $5.623 \times 10^{-4}$ & 0.294 \\
\hline
\end{tabular}

Source: own study in MALTAB Neural Network Toolbox.

TABLE 13: Values of MSE and $R$ depending on the division of the training set (for two neurons in the hidden layer and TRAINLM algorithm) in model ANN 4.

\begin{tabular}{lcc}
\hline Division of the training set & MSE value & $R$ value \\
\hline $70 \% / 15 \% / 15 \%$ & $4.184 \times 10^{-4}$ & 0.266 \\
$80 \% / 10 \% / 10 \%$ & $8.032 \times 10^{-4}$ & -0.062 \\
\hline
\end{tabular}

Source: own study in MALTAB Neural Network Toolbox.

lowest error value was obtained for the LevenbergMarquardt algorithm (Table 3) with the structure of $70 \% / 15 \% / 15 \%$ division of the training set (Table 4 ).

The final stage of this part of research was to predict the value of a satellite signal parameter (position error). Therefore, in Figure 1, the last nine samples that were subjected to the forecast were demonstrated and compared with the real values.

In the light of carried research, it is worth noting that the difference between the largest and the smallest accuracy errors expressed by the average HNSE and VNSE values for the nine samples taken to the forecast was only $1.185 \mathrm{~m}$ and that in the forecast itself was only $0.087 \mathrm{~m}$.

In Table 5, the MSE error values and $R$ indicator for different numbers of neurons in the hidden layer for model ANN 2. Continuity were presented. Many networks were tested, but the most representative results were seen for networks with one, two, five, eight, or ten neurons in the hidden layer. The lowest error value was obtained for the LevenbergMarquardt algorithm (Table 6) with the structure of $80 \% / 10 \% / 10 \%$ division of the training set (Table 7 ). 


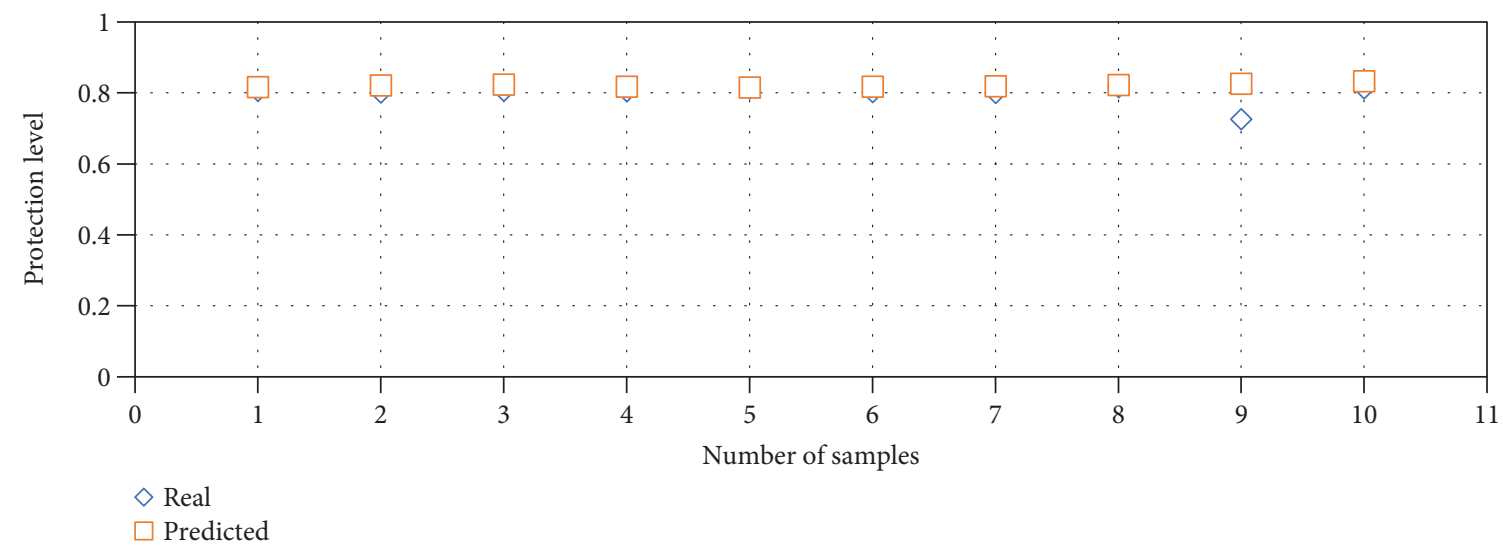

FIGURE 4: Comparison of the forecast and actual protection level of the signal.

Similarly, the final stage was to predict value of a satellite signal parameter (number of discontinuity events). Therefore, in Figure 2, the last nine samples that were subjected to the forecast were demonstrated and compared with the real values.

It is worth noticing that the difference between the largest and the smallest values of discontinuity events for the nine samples taken to the forecast was 13 and that in the forecast itself was 10 .

In Table 8, the MSE error values and $R$ indicator for different numbers of neurons in the hidden layer for model ANN 3. Availability were presented. Many networks were tested, but the most representative results, similar to those of the previous model, were seen for networks with one, two, five, eight, or ten neurons in the hidden layer. Lower error value was achieved for the Levenberg-Marquardt algorithm (Table 9) with the structure of 70\%/15\%/15\% division of the training set (Table 10).

The last part of modelling availability was to predict the value of a satellite signal parameter. In Figure 3, the last ten samples that were subjected to the forecast were demonstrated and compared with the real values.

The difference between the highest and lowest value of availability expressed in \% in the case of ten samples taken to the forecast amounted only $0.779 \%$, and that in the forecast itself amounted 1.209\%. In this model, despite of difficult to analyze data (concentrated at the value of $1=100 \%$ ), the smallest MSE error value and the best results were obtained.

In Table 11, the MSE error values and $R$ indicator for different numbers of neurons in the hidden layer for model ANN 4. Integrity were presented. Many networks were tested, but the most representative results, similarly to those of two previous models, were seen for networks with one, two, five, eight, or ten neurons in hidden layer. Lower error value was achieved for the Levenberg-Marquardt algorithm (Table 12) with the structure of $70 \% / 15 \% / 15 \%$ division of the training set (Table 13).

In Figure 4, the last ten samples that were subjected to the forecast were demonstrated and compared with the real values.

The difference between the highest and lowest integrity values expressed by the protection level for ten samples taken to the forecast was only 0.091 , and that in the forecast itself amounted 0.018. Small differences between data values caused great difficulties in training this network. The results, however, indicate that the network coped with such a problem and, finally, a near-real estimation of the signal integrity was obtained.

\section{Conclusions}

The paper attempted to answer the question on how to facilitate selection of navigation techniques for the aircraft operator, taking into account factors determining the accuracy, continuity, availability, and integrity of the satellite signal. As a result, the purpose of the work was defined as development of a method for forecasting the values of satellite navigation signal parameters used in air transport by artificial neural networks, taking into account selected atmospheric conditions. Results included in the work indicate further directions of satellite navigation system development

There is a clearly visible interest in the issues of implementing satellite techniques for various areas of air traffic. It is possible to see a series of conducted research on both the operational parameters of satellite systems and the satellite signal itself. Still, it is important to notice that meteorological conditions in any area of aviation should not be underestimated due to their wide impact-the use of a GPS system entails the necessity to correct errors in determining the position caused by atmosphere or signal reflection.

It was found that the reasons for the limited operational use of satellite systems can be found in technical, organizational, or administrative aspects. Those connected with satellite communication require very precise legal regulations and international cooperation. Others, of a technical nature, occur in the form of errors or signal interference. International law is another aspect affecting satellite activity. In addition, the literature on the subject indicates that the evolution of satellite systems will include, among others, better protection of the signal against intrusive interference with its structure, more attention to tropospheric and ionospheric delay, advanced work on legal regulations improving the implementation of satellite navigation systems in civil aviation, and adaptation of aircraft fleet to receive satellite signals. 
Usually, for analysis of phenomena related to the satellite signal used for operational use in civil aviation, the model research is used. Experimenting on a real air operation can lead to dramatic effects. Therefore, numerous attempts were made to study signal interference and processes occurring in satellite systems during operation that have a potential impact on its reception. Models of artificial neural networks for the prediction of satellite signal parameters have been developed in this article. The publication includes, among others,

(i) design of artificial neural network models for the undertaken research problem

(ii) implementation of models in the MATLAB Neural Network Tool environment

(iii) analysis of test results

(iv) comparison of model results with real data

The results allow to state that it is possible to forecast values of satellite navigation signal parameters used in air transport thanks to artificial neural networks. The verification of models through the comparison of the results with the real data also contributed to this. The authors of numerous scientific publications have proved that neural networks optimally work as a tool for modeling values of various parameters and, what is more, also for their forecasting. The necessary, adequate amount of data is a prerequisite for their use. In fact, ANN already have their application in the field of satellite systems $[4,6,18,22]$; they are also a popular and valuable tool in the research on other phenomena occurring in air traffic, especially during aircraft takeoff and landing operations. Undoubtedly, their advantage is the possibility of predicting phenomena and its graphic visualization in comparison to real data. Positive verification of models and leaving the possibility of extending them generate the prospect of conducting further research, including, for example:

(i) extension of ANN models with new input variables

(ii) creating an online application dedicated to users, displaying the values of satellite signal parameters in real time along with a predefined prediction, for example, for the next two hours, taking into account all available data on signal-interfering factors

(iii) provision of signal forecast data via a dedicated application for general aviation users and VFR (visual flight rules) operators

(iv) creating an application for an unmanned aircraft that automatically determines the choice of navigation technique

(v) enabling dense aggregation of data (e.g., within every minute) from satellite signal parameters and atmospheric conditions by building a reference station with an adapted database and data storage, which will facilitate the creation of a model with more precise forecast

\section{Data Availability}

The measurements of EGNOS parameters used to support the findings of this study are available from the corresponding author upon request.

\section{Conflicts of Interest}

The authors declare that they have no conflicts of interest.

\section{References}

[1] K. Krzykowska, M. Siergiejczyk, and A. Rosiński, "Influence of selected external factors on satellite navigation signal quality," in Safety and Reliability - Safe Societies in a Changing World, pp. 701-705, CRC Press, 2018.

[2] A. Nickitopoulou, K. Protopsalti, and S. Stiros, "Monitoring dynamic and quasi-static deformations of large flexible engineering structures with GPS: accuracy, limitations and promises," Engineering Structures, vol. 28, no. 10, pp. 1471-1482, 2006.

[3] C. Ogaja, C. Rizos, and S. Han, "Is GPS good enough for monitoring the dynamics of high-rise buildings?," in Proceedings of the 2nd Trans Tasman Surveyors Congress, Queenstown, New Zealand, 2000.

[4] Z. Zhu and C. Li, "Study on real-time identification of GNSS multipath errors and its application," Aerospace Science and Technology, vol. 52, pp. 215-223, 2016.

[5] H. Liu, L. Xu, B. Shu, M. Zhang, and C. Qian, "A new method to improve the performance of multi-GNSS pseudorange positioning in signal-degraded environment," Advances in Space Research, vol. 58, no. 4, pp. 577-586, 2016.

[6] C. Ordóñez Galán, J. R. Rodríguez Pérez, S. García Cortés, and A. Bernardo Sánchez, "Analysis of the influence of forestry environments on the accuracy of GPS measurements by means of recurrent neural networks," Mathematical and Computer Modelling, vol. 57, no. 7-8, pp. 2016-2023, 2013.

[7] C. Ordóñez Galán, J. R. Rodríguez-Pérez, J. Martínez Torres, and P. J. García Nieto, "Analysis of the influence of forest environments on the accuracy of GPS measurements by using genetic algorithms," Mathematical and Computer Modelling, vol. 54, no. 7-8, pp. 1829-1834, 2011.

[8] H. Hasegawa and T. Yoshimura, "Estimation of GPS positional accuracy under different forest conditions using signal interruption probability," Journal of Forest Research, vol. 12, no. 1, pp. 1-7, 2007.

[9] J. Oliveira and C. Tiberius, "Quality control in SBAS: protection levels and reliability levels," Journal of Navigation, vol. 62, no. 3, p. 509, 2009.

[10] Y. Yang and J. Xu, "GNSS receiver autonomous integrity monitoring (RAIM) algorithm based on robust estimation," Geodesy and Geodynamics, vol. 7, no. 2, pp. 117-123, 2016.

[11] H. Xu, J. Wang, and X. Zhan, "GNSS satellite autonomous integrity monitoring (SAIM) using inter-satellite measurements," Advances in Space Research, vol. 47, no. 7, pp. 11161126, 2011.

[12] I. Rodríguez, C. García, C. Catalán et al., "Satellite autonomous integrity monitoring (SAIM) for GNSS systems," in Proceedings of the 22nd International Technical Meeting of the Satellite Division of The Institute of Navigation (ION GNSS 2009), pp. 1330-1342, Savannah, GA, USA, 2009. 
[13] S. Hewitson and J. Wang, "GNSS receiver autonomous integrity monitoring (RAIM) performance analysis," GPS Solutions, vol. 10, no. 3, pp. 155-170, 2006.

[14] E. Sardón, A. Rius, and N. Zarraoa, "Estimation of the transmitter and receiver differential biases and the ionospheric total electron content from global positioning system observations," Radio Science, vol. 29, no. 3, pp. 577-586, 1994.

[15] A. J. Mannucci, B. D. Wilson, D. N. Yuan, C. H. Ho, U. J. Lindqwister, and T. F. Runge, "A global mapping technique for GPS-derived ionospheric total electron content measurements," Radio Science, vol. 33, no. 3, pp. 565-582, 1998.

[16] R. Warnant, I. Kutiev, P. Marinov, M. Bavier, and S. Lejeune, "Ionospheric and geomagnetic conditions during periods of degraded GPS position accuracy: 1. Monitoring variability in TEC which degrades the accuracy of real-time kinematic GPS applications," Advances in Space Research, vol. 39, no. 5, pp. 875-880, 2007.

[17] P. Yin and C. N. Mitchell, "Demonstration of the use of the Doppler Orbitography and Radio positioning Integrated by Satellite (DORIS) measurements to validate GPS ionospheric imaging," Advances in Space Research, vol. 48, no. 3, pp. 500-506, 2011.

[18] J. B. Habarulema, L. A. McKinnell, and B. D. L. Opperman, "Towards a GPS-based TEC prediction model for Southern Africa with Feed forward networks," Advances in Space Research, vol. 44, no. 1, pp. 82-92, 2009.

[19] D. Sur and A. Paul, "Comparison of standard TEC models with a neural network based TEC model using multistation GPS TEC around the northern crest of equatorial ionization anomaly in the Indian longitude sector during the low and moderate solar activity levels of the 24th solar cycle," Advances in Space Research, vol. 52, no. 5, pp. 810-820, 2013.

[20] J. B. Habarulema, L.-A. McKinnell, and P. J. Cilliers, "Prediction of global positioning system total electron content using neural networks over South Africa," Journal of Atmospheric and Solar-Terrestrial Physics, vol. 69, no. 15, pp. 1842-1850, 2007.

[21] S. I. Oronsaye, L. A. McKinnell, and J. B. Habarulema, "A new global version of $\mathrm{M}(3000) \mathrm{F} 2$ prediction model based on artificial neural networks," Advances in Space Research, vol. 53, no. 3, pp. 371-386, 2014.

[22] Q. Wang, Y. Li, M. Diao, W. Gao, and Z. Qi, "Performance enhancement of INS/CNS integration navigation system based on particle swarm optimization back propagation neural network," Ocean Engineering, vol. 108, pp. 33-45, 2015.

[23] C. Berezowski, Międzynarodowe Prawo Lotnicze, Polskie Wydawnictwo Naukowe PWN, Warsaw, Poland, 1964.

[24] M. Żylicz, Prawo lotnicze międzynarodowe, europejskie $i$ krajowe, LexisNexis, Warsaw, Poland, 2011.

[25] "Convention for the Suppression of Unlawful Seizure of Aircraft, Signed at the Hague, on 16 December 1970 (The Hague convention 1970)," 1970.

[26] "Convention for the suppression of unlawful acts against the safety of civil aviation (with Final Act of the International Conference on Air Law held under the auspices of the International Civil Aviation Organization at Montreal in September 1971)," 1971.

[27] J. Januszewski, "How the ionosphere affects positioning solution using terrestrial and satellite navigation systems?," in Telematics in the Transport Environment, pp. 249-257, Springer, 2012.
[28] G. E. Davis Jr. and W. E. Lowell, "Solar cycles and their relationship to human disease and adaptability," Medical Hypotheses, vol. 67, no. 3, pp. 447-461, 2006.

[29] M. Siergiejczyk, K. Krzykowska, and A. Rosiński, "Evaluation of the influence of atmospheric conditions on the quality of satellite signal," in Proceedings of the 12th International Conference on Marine Navigation and Safety of Sea Transportation (TransNav 2017), pp. 95-103, Gdynia, Poland, 2017.

[30] M. Siergiejczyk, K. Krzykowska, and A. Rosinski, "Parameters analysis of satellite support system in air navigation," in Progress in Systems Engineering, pp. 673-678, Springer, 2015.

[31] R. Tadeusiewicz and M. Szaleniec, Leksykon sieci neuronowych, Wydawnictwo Fundacji "Projekt Nauka", Wrocław, Poland, 2015. 


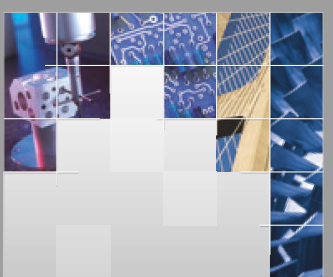

\section{Enfincering}
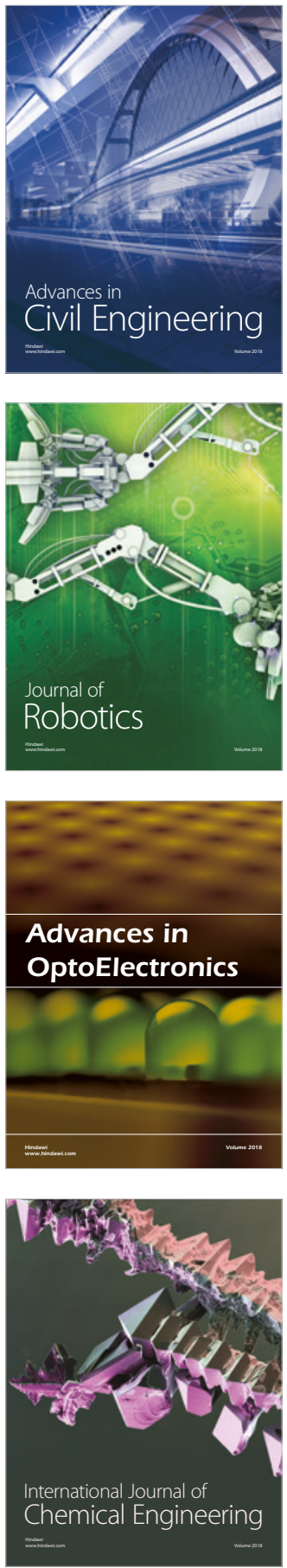

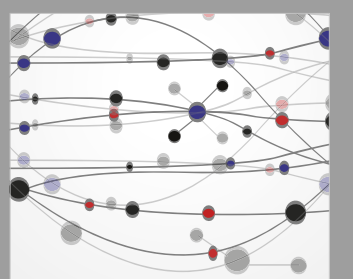

\section{Rotating \\ Machinery}

The Scientific World Journal

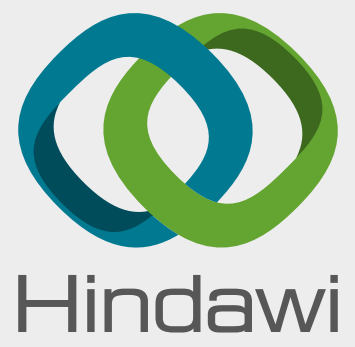

Submit your manuscripts at

www.hindawi.com
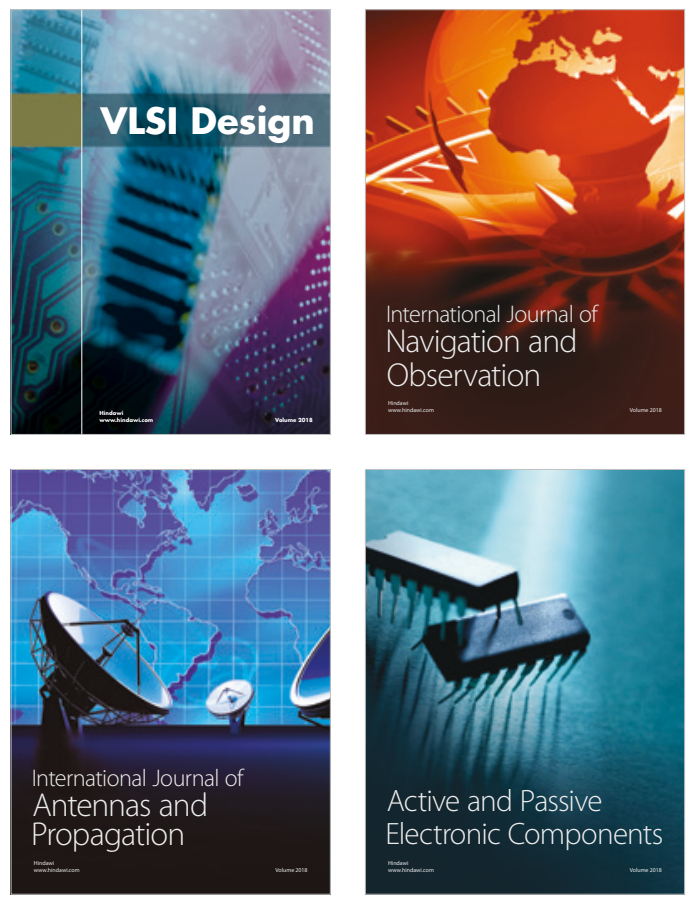
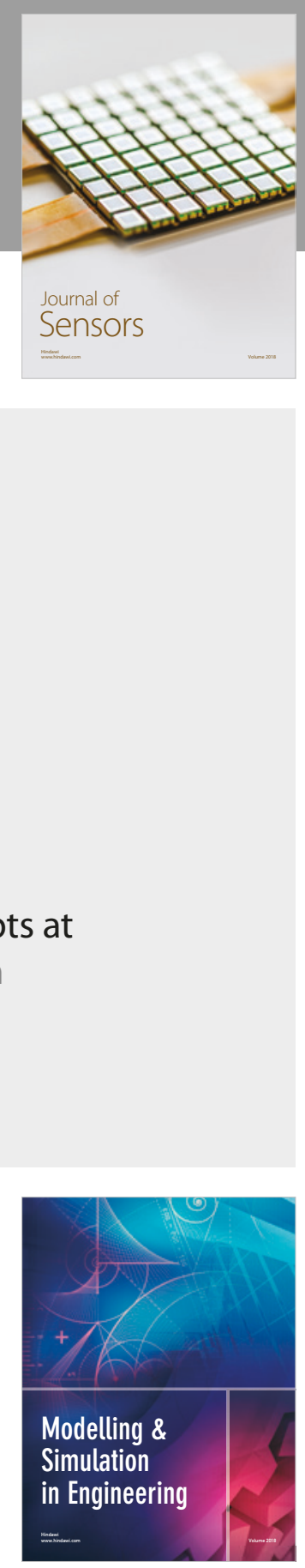

\section{Advances \\ Multimedia}
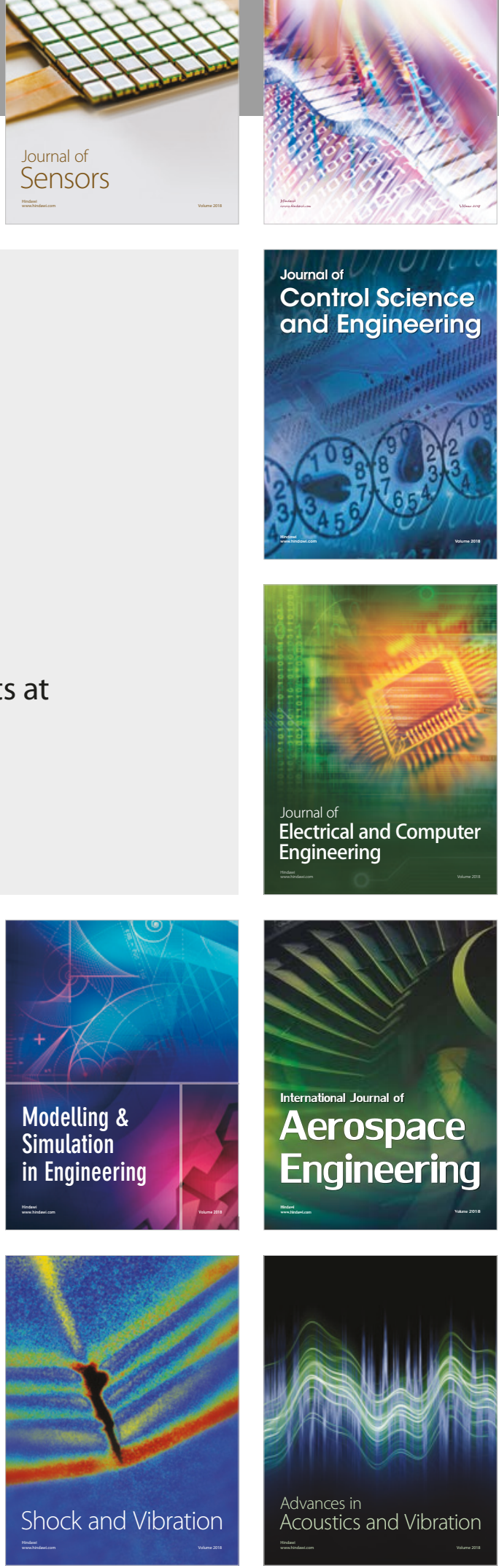